\title{
Mothers' Cooking: Perspectives of Givers and Takers
}

\section{Amavasee Ampansirirat ${ }^{1}$, Siriwan Chukumnird ${ }^{2, *}$, Prapaipis Singhasem ${ }^{3}$, Marisa Suwanraj ${ }^{2}$ and Kornwika Phromjuang ${ }^{4}$}

\author{
${ }^{I}$ Boromarajonani College of Nursing, Chiang Mai, Faculty of Nursing, Praboromarajchanok Institute, \\ Chiang Mai 50180, Thailand \\ ${ }^{2}$ Boromarajonani College of Nursing, Songkhla, Faculty of Nursing, Praboromarajchanok Institute, \\ Songkhla 90000, Thailand \\ ${ }^{3}$ Boromarajonani College of Nursing, Trang, Faculty of Nursing, Praboromarajchanok Institute, Trang \\ 92000, Thailand \\ ${ }^{4}$ Boromarajonani College of Nursing, Buddhachinaraj, Faculty of Nursing, Praboromarajchanok \\ Institute, Phitsanulok 65000, Thailand
}

('Corresponding author’s e-mail: scsiriwanch@gmail.com)

Received: 27 October 2020, Revised: 21 May 2021, Accepted: 27 May 2021

\begin{abstract}
The burden of malnutrition of children is a global challenge. Promoting mothers to prepare their own meals at home is indicated as an important strategy to prevent malnutrition and improve nutrition in children. Despite the fact that meals prepared by mothers are healthier, little is known about what cooking means in the Thai context. This descriptive qualitative research is intended to describe the perceptions and perspectives of mothers' cooking among Thai mothers and school-age children. Descriptive qualitative research, using in-depth interviews with 10 mothers aged 31 to 80 years old and 10 school-age children aged 10 to 12 years old, was conducted. Participants were selected using purposive sampling from 10 sub-districts that are partners of the mothers' cooking network project of Songkhla province. Data were analyzed using content analysis. The results provided by the mothers' and children's perspectives indicated that Thais perceived mothers' cooking quite differently based on whether the perspective toward mothers is as the giver or whether the children addressed the perspective of the taker. For the giver, mothers' cooking was defined in terms of the power of love, happiness time, feeling of selfworth, and mother's role and responsibility. For the taker, mothers' cooking was defined in terms of the best thing and the most delicious, family relationship, giving and sharing, and demonstration of love and care. Additionally, this study highlighted that the mother's perception of cooking can be divided into 3 steps, namely, preparation, cooking and eating together. These findings may help in determining how public health programs can be improved and the role of mothers promoted within a healthy nutrition strategy.
\end{abstract}

Keywords: Mothers' cooking, Perspective of givers, Perspective of takers

\section{Introduction}

Malnutrition remains a significant children's health concern because it impacts on serious health issues and development, including increased vulnerability to illness, stunted growth and developmental delays [1]. Despite the implementation of various policies and programs worldwide, recent global data found in 2019 that $21.3 \%$ of all children under 5 years of age were stunted, $7.3 \%$ wasted, and $5.6 \%$ overweight [2]. Thailand, like some other developing countries, is facing a growing double burden of malnutrition, characterized by the coexistence of both under- and overnutrition. In 2016, stunting affected the lives of an estimated $11 \%$ of children under 5 years and wasting continued to threaten the lives of an estimated $5 \%$, while an overweight condition impacted an estimated $8.2 \%$ [3].

Provision of optimal nutrition during childhood is critical to good health, growth and development. A mother is perceived as one who is responsible for preparing food for her children and family. She is seen as a primary family member both during and after pregnancy because she is important in laying a healthy foundation for her children. "Mother's cooking" is still a significant practice in Thai culture and everyday life for Thais. Food prepared by mothers continues to play an important role in family life, not only in terms of body function and well-being, but also in terms of its symbolic value as a means of 
forming a family. Mealtime is a source of pride for many families because it brings family members together. It allows everyone in the family to gain a better understanding of one another. This is a time for Thai families to chat, bond and create memories together. The majority of previous research in this field has concentrated on the frequency of family meals for children as a predictor of psychological well-being or nutrient intakes in children [4].

Promoting and encouraging families to prepare their own meals at home are indicated as an important strategy to prevent malnutrition and improve nutrition in children [5-7]. Because the household's mother plays a central role in promoting the health and development of children, provision of optimal nutrition during childhood should focus on the mother. Moreover, the mother can provide an opportunity to determine health outcomes and nutrition status by improving nutritional intake and establishing healthy eating habits [8]. Although home cooking is thought of as a vital activity in the daily life and culture of a mother, recent studies found that the frequency of family meals tends to decrease worldwide [9].

Family meals are associated with many positive aspects for family members, particularly, improved behavior outcomes for children and quality time spent with family members $[10,11]$. However, one of the biggest challenges facing mothers is that preparing and cooking meals on a routine daily basis for family members are not easy tasks. There are many reasons why mothers find it difficult to continue a commitment to preparing and cooking for their children. Some of these reasons are a lack of time, daily pressure, smaller households and cooking stress [12,13]. Research shows that Thai households, like those in many countries, are now less likely to prepare their own meals to eat at home [14]. Food purchases that are quicker and easier to prepare are becoming more common, even in rural areas, because of time pressures and the busy lives of mothers. Analyses of data from the Fifth National Health and Nutrition Examination Survey (NHANES V) found that about $53.3 \%$ of the Thai population skipped breakfast, while $29.6 \%$ skipped lunch and $12 \%$ were dining out. Between the ages of 15 and 29 years the majority of meals are street food [15].

Although home cooking is integrated into the daily life of Thai families, little is known about Thais' perspectives on mothers' cooking. There were limitations in the studies on the concept of mothers' cooking that were reviewed. One was that the mothers' cooking was regularly consumed without any explanation or clear definition [16]. Terms commonly associated with the mother making food ready to eat in the context of family meals include "mothers' food," "homemade" and "home cooking" [16-18]. The meaning of mothers' cooking in the Thai context is not well understood. Most existing studies have been conducted outside of Thailand and may lack relevance to Thais $[4,19]$. Furthermore, there is a gap between how society views and what mothers expect of mothers' cooking. This paper addresses this gap using essay elicitation interview data from a qualitative study to explore the perceptions of mothers and school-age children regarding the complex meaning of mothers' cooking.

Improvement in knowledge about this concept is essential as a greater frequency of cooking at home is associated with children's consumption of a healthier diet [6]. These results may help clearly identify how public health programs can be better designed to promote the role of mothers in a healthy nutrition strategy. The purpose of this study was to explore the perceptions of Thai individuals about concepts related to mothers' cooking. The specific aims of this formative research are to 1) explore meanings of mothers' cooking from the perspectives of Thai mothers who report success in preparing and cooking family meals and 2) explore meanings of mothers' cooking from the perspectives of Thai school-age children.

\section{Materials and methods}

\section{Study design}

This research used a descriptive qualitative study design with in-depth interviews and an essay entitled "Mothers' Cooking" to explore "mothers' cooking" perceptions among Thai mothers and children. Qualitative descriptive design enables researchers to obtain insights of study participants' experiences in their own language, without the interpretation of existing theories. [20,21]

\section{Informants and setting}

Informants were selected using purposive sampling from 10 sub-districts that are partners of the mothers' cooking network project of Songkhla province (Pawong, Khuan Roo, Bo Yang, Nam Noi, Chalae, Natawee, Tha kham, Thepa and Ranot). Sampling was performed on mothers and children with maximum variation as to age range, level of education and occupation, until the data were saturated with the participation of 10 mothers and 10 children. The eligibility criteria for mother informants were 
1) identified by their community members as mothers who were currently cooking meals on a routine daily basis or had prior cooking meal experience and 2) received an Outstanding Mother Award from the mothers' cooking network project of Songkhla province. The eligibility criteria for children informants were 1) identified by their teachers as children who are in primary school grades 4 to 6 and 2) participated in an essay contest entitled "mother's food" from their school.

\section{Data collection}

Individual in-depth interviews were conducted by the researcher to elicit depth of valuable information and to gain insights related to participants' perspectives and realities. Semi-structured faceto-face interviews were carried out at the participant's home by appointment between October 2016 and August 2017. Open-ended questions were developed based upon a review of the literature and were adjusted by 3 experts in a qualitative study to make them appropriate to the informant and the context.

Table 1 Interview guidelines

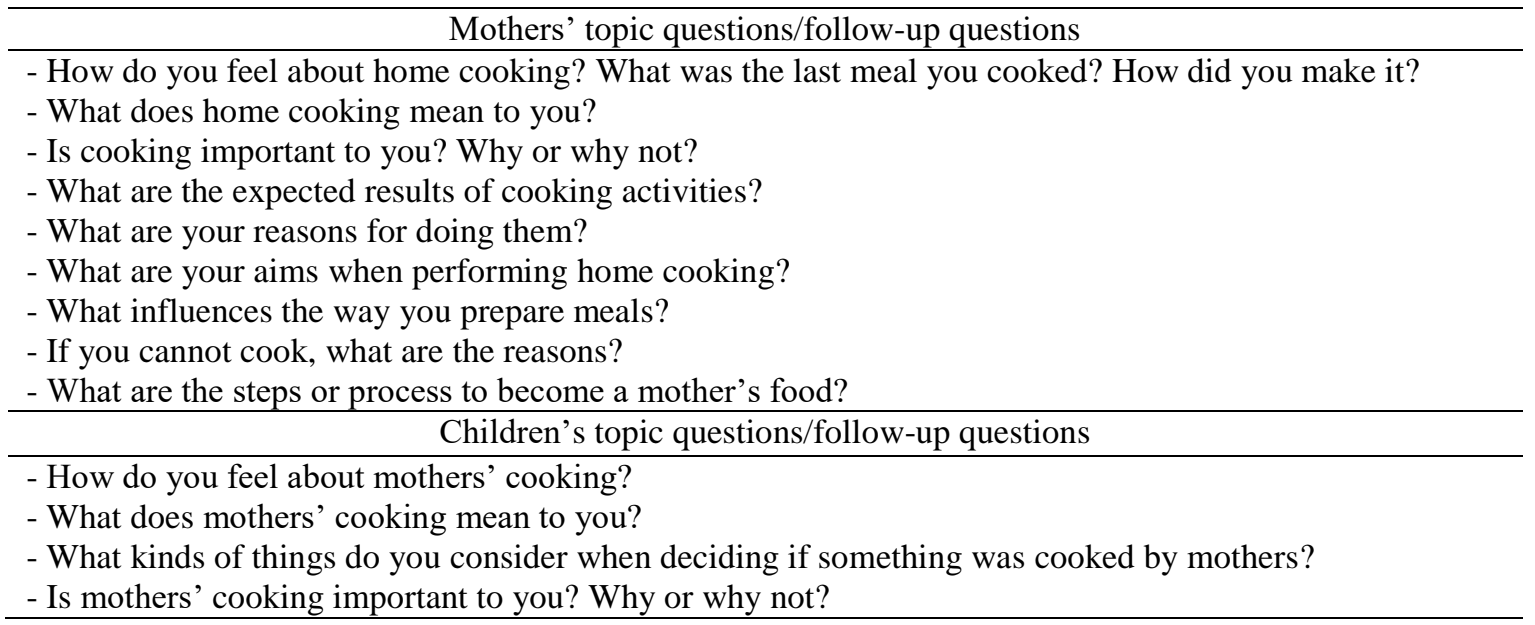

Each interview varied from 40 to 60 min and was recorded with the participants' informed consent. Interviewing continued until researchers deemed data saturation to have been occurred. Data saturation occurred when existing themes were consistently repeated, and no new themes emerged from the data [22]. Field notes were written during the interviews to capture the important information [23]. After data collection, the data were transcribed verbatim into written text immediately and checked for accuracy after the interviews took place [24]. Background information on the participant was collected at the end of the interviews. The present study also used an essay entitled "Mothers' Cooking" to gain a more in-depth understanding of children's experiences and, in this case, explore the perceptions of mothers' cooking.

\section{Data analysis}

A content analysis approach was used to analyze the qualitative data. The meanings of mothers' cooking were analyzed to determine unique characteristics derived from individual lifestyles and experiences. After all interviews were transcribed verbatim into written text, data were coded and themed by being carefully read several times and marking the word or short phrase from the text in order to identify and capture key concepts. The similar codes were combined to form categories. The sorting of various categories into themes was created in a table. Many of these items expressed similar ideas that could be developed into themes.

\section{Ethics review}

The study was reviewed and approved by the Institutional Review Board of Boromarajonani Songkhla Nursing College, Thailand. (Ethical number, BCNSK 7-8/2560, BCNSK 15-16/2560, BCNSK 20-22/2560). All participants who met the recruitment criteria received written and verbal explanations about the objectives of the study, voluntary participation, protocols of the study and the right to withdraw from participation in the study at any time without consequences. In-depth interviews were conducted after the researcher obtained informed consent from the participant. Parents gave written consent for their 
children. Before the interviews began, the children gave verbal assent. Children participants were asked to take an essay entitled "Mother's cooking", which they would then present and discuss during the interview. Confidentiality was assured by replacing identified names with pseudonyms, and all transcripts and audiotapes were kept in a locked file cabinet until completion of the study.

\section{Trustworthiness of qualitative data}

Trustworthiness of this research was accomplished by utilizing the criteria proposed by Lincoln and Guba [25]. Credibility was enhanced by member checking the data. Interview participants were asked during and after the interviews to confirm the researcher's interpretation. With respect to dependability, 3 qualitative researchers examined research-related documents and validated the data.

\section{Results and discussion}

The mothers of different ages and school-age children of this study participated in cooking practices that reflect different perspectives, which occurred in different personal, family and social contexts. Participants also perceived "mothers' cooking" is related to family meals and home cooking. They identified the meaning and elements of "mothers" cooking" and talked about a complexity of relationships between motherhood, food, emotional and social values.

Table 2 Mothers and children participants' characteristics

\begin{tabular}{|c|c|c|c|c|c|c|c|c|c|}
\hline \multicolumn{2}{|l|}{ Gender (N) } & \multicolumn{2}{|c|}{ Marital status (N) } & \multicolumn{2}{|l|}{$\operatorname{Age}(\mathbf{N})$} & Education (N) & \multicolumn{3}{|c|}{ Occupation (N) } \\
\hline Mother & 10 & Single & 2 & $31-40$ & 1 & Less than & - & Agriculturist & 5 \\
\hline \multirow[t]{6}{*}{ Female } & & & & $41-50$ & 6 & Primary school & & & \\
\hline & & Married and & 6 & $51-60$ & 2 & Primary school & 1 & Government Official & 2 \\
\hline & & living together & & $61-70$ & - & Secondary school & 6 & & \\
\hline & & Widowed & 2 & $71-80$ & 1 & Bachelor's degree & 2 & Housewife & 1 \\
\hline & & & & & & Master's degree & 1 & Self-employed & 1 \\
\hline & & & & & & & & Businesswoman & 1 \\
\hline Children & & & & & & Primary school & & & \\
\hline \multirow[t]{3}{*}{ Female } & 6 & & & 10 & 1 & Grade 4 & & & \\
\hline & & & & 11 & 1 & Grade 5 & & & \\
\hline & & & & 12 & 3 & Grade 6 & & & \\
\hline \multirow[t]{4}{*}{ Male } & 4 & & & & & & & & \\
\hline & & & & 10 & 0 & Grade 4 & & & \\
\hline & & & & 11 & 2 & Grade 5 & & & \\
\hline & & & & 12 & 3 & Grade 6 & & & \\
\hline
\end{tabular}

Table 3 Themes and initial coding framework

\begin{tabular}{cl}
\hline Theme (final coding framework) & \multicolumn{1}{c}{ Initial coding framework } \\
\hline Mothers' interviews & \\
Power of love & $\begin{array}{l}\text { 1. Mother's love } \\
\text { 2. Mothers always cook for children } \\
\text { 3. Devoting time for cooking } \\
\text { 4. Preparing good and healthy food } \\
\text { 5. Children are happy and healthy }\end{array}$ \\
\hline \multirow{2}{*}{ Happiness time } & $\begin{array}{c}\text { 1. Happiest task } \\
\text { 2. Happy time }\end{array}$ \\
\hline \multirow{2}{*}{ Feelings of self-worth } & 1. Self-identified as a good cook \\
& 2. Feeling proud and happy \\
\hline \multirow{2}{*}{ Mother role and responsibility } & 1. Self-identification as a mother \\
2. Mother's role
\end{tabular}




\begin{tabular}{ll}
\hline Theme (final coding framework) & \multicolumn{1}{c}{ Initial coding framework } \\
\hline \multicolumn{1}{c}{ Children's perspectives } & \\
The best thing and the most delicious & $\begin{array}{l}\text { 1. Food cooked by mom tastes the best } \\
\text { 2. Impression of mother's food } \\
\text { 3. Benefits of mother's food } \\
\text { 4. Positive memories of mother's cooking }\end{array}$ \\
\hline \multirow{2}{*}{ Family relationship } & $\begin{array}{l}\text { 1. Mother's love and relationship } \\
\text { 2. Perception on family relationship }\end{array}$ \\
\hline \multirow{2}{*}{ Giving and sharing } & $\begin{array}{l}\text { 1. Mother's sacrifice for children } \\
\text { 2. Mother always gives good food to children }\end{array}$ \\
\hline \multirow{2}{*}{ Demonstration of love and care } & $\begin{array}{l}\text { 1. Made with love } \\
\text { 2. Mothers want the child to be healthy. }\end{array}$ \\
3. Mother's cooking is full of love and care
\end{tabular}

\section{Mothers' cooking: Givers and takers' perspectives (mothers' interviews) \\ Power of love}

Interviewed mothers identified with the ideal of mothers' cooking and spoke about feeling and perception of their cooking. Mothers used the actions and food products of mothers' cooking to be a symbol for the "power of love" for mothers who cook and for children who receive feeding from mothers. "Power of love" was viewed as emotional values that representing the mother's continuing commitment to cook the best food for the children and family. This value is the result of natural association between mothering, love and food. Mothers' cooking is an act of love that is passed down between mother and children for keeping her children happy and healthy as described by 3 participants.

"You know what, if you've got a kid with a good diet that's happy and healthy, to me that's everything. I always cook for them. I hope they understand how very much I love them and that if nothing else, they feel that through my cooking." (Mother No. 6, 20 October 2016)

"For my children, I cannot say that I don't have time for cooking. Even though I am busy and not enough time, I always cook for them." (Mother No. 7, 20 November 2016)

"Mothers' cooking" sounds like mom prepared a good food for their children. Food cooking for our loved ones must be devoted. I think that sometimes food needs to be fun to encourage my son to eat. It's mainly that my son is happy and healthy with what he is eating and what he is getting." (Mother No. 4, 10 October 2017)

\section{Happiness time}

The second theme that emerged from interviewed mothers about their home cooking experience is happiness time. This theme was viewed as a sense of an internally motivated use of time. Mothers do not see cooking for their children as a burden, but rather as activities that they enjoy doing. Interviewed mothers also felt it could easily become satisfying even during busy days. They emphasized their positive feelings in day-to-day food provisioning activities, particularly spending their time cooking. For them, provision of family food brings happiness and enjoyment to their lives, these experiences were identified by:

"Even though it's busy, we must cook food for our kids. 'Housewife' jobs are the happiest task." (Mother No. 1, 4 December, 2016)

"I am so happy of cooking for my child, it is a really happy time for me." (Mother No. 5, 13 October, 2016)

\section{Feelings of self-worth}

Interviewed mothers explained that cooking for their children can help raise tremendous selfconfidence and self-worth. Mothers were very proud of themselves when their children talked about their cooking and gave their comments about the food. These comments can be viewed as the power that children exerted over their mothers' views of themselves, as described by 2 participants:

"Cooking for kids, when cooking, we are so happy and proud of me.... When cooking for kids, after finishing cooking, mom felt happy. The more my kids said delicious, the happier and relaxed. Especially, 
when hearing the words such as "this taste really good" or "this is so amazing" it makes me feel great. I still cooking until my children were growing up." (Mother No. 5, 13 October, 2016)

"When my kid told me that mom tomorrow, please cook a great menu that I love to eat for me, please. I felt so proud of myself that my kid trusts me. For mother's food, this word makes me feel that I do for my kid and give food for my beloved kid to eat. Thus, we have to take care them. We focus that our kids like it and highlight on safety for our kids." (Mother No. 2, 20 October, 2016).

\section{Mother role and responsibility}

Interviewed mothers seemed to understand that they perform the majority of work associated with food and often feel that it is a part of their role as "mother" to prepare meals for members of their families. Mother's role and responsibility were also viewed as social values that are a key personal duty for mom to cook for their child. Despite the daily challenges of working, cooking for their children was a vital part of their self-identification as a mother. Interviewed mothers explained that cooking was not a burden; they described that preparation of food is very important in the everyday life of mothers and accepted this as their self-evident roles, as described by 1 participant:

"For my kid, I could not say "I don't have time, yep!! Even though I am busy, I always have time to cook for my baby because I am a mother.” (Mother No 8. 20 November, 2517)

Interviewed mothers viewed themselves as nutritional gatekeepers of their children's diet. They considered cooking as a principal responsibility for how those children achieve successful health and well-being, as described by 1 participant:

"Actually, mother's food, it had to take care since a baby in utero. We should know what types of foods we should eat, how to practice, and take care of mom to get healthy. Yes!! We must eat complete 5 food groups. We should enrich with ferrous mineral from green veggies around our house, promote exercise, consume vegetables to increase breast milk such as broccoli and banana." (Mother No.3, 6 August, 2017)

\section{Kids' perspectives}

\section{Mother's cooking is the best thing and the most delicious}

Interviewed children often described their perception of the positive memories of the experiential pleasure of mother's cooking. The best and delicious food was viewed as part of children's impression of their mothers. Whenever they eat a mother-cooked meal, they will show gratitude and pleasure and express how their mothers' food is different. Memories of mother's cooking are powerful things. The sight of their mother cooking and the smells and delicious flavors can stay in the mind forever, and it becomes the token of reminder for home and family affection. Most participants in this study always miss their mothers' cooking, as explained by 4 participants:

"When I miss the mother's cooking, I always miss the delicious food such as my mom used to cook delicious congee with Xiang Jee and sprinkled with coriander." (A child in primary school, sixth grade, and the third school, on October 10,2016)

"Even though the mother's cooking is not delicious like other mom cooks, I am so proud for my mother's craft food that make me impressed and like most." (A child in primary school, sixth grade, and in the first school, on August 3, 2017)

“The mother's cooking has plenty of benefits. There are a lot of menus that my mom cooks delicious such as soup, boiled pork bone soup and sour curry. My mom does the best thing for me. I won't forget her gratitude." (A child in primary school, sixth grade, and in the second school, on August 3, 2017)

"For mother's food, I always though previously it is delicious and ate my fill...nobody can compare her food." (A child of a good mother role model sixth, on September 2, 2017)

"For mother's food, there are many things that are the most impressive. The mother will only make healthy food and make the body strong. Mom always cooks." (A child in primary school, fifth grade, and in the seventh school, on August 3, 2017)

Children in different ages of this study were eager to talk about their mothers' cooking and said they love eating at home because it is delicious and healthy. Children seemed to use the investment in and devotion to cooking by their mothers as a key to affirm the ideas about good motherhood. Most of them perceived that food is significant to health and also mentioned that mothers' cooking can influence both childhood and adult health because mothers consciously tried to provide a healthy meal and to encourage healthy eating behaviors. These experiences were declared as follows:

"Other foods were perfectly selected and cooked by my mom for all people in our family such as stir-fried crab curry powder. My mom bought fresh crab and garnish from a quality shop. Eggs also were brought from the chicken coop to make an omelet. My mom was always concerned about clean food to 
make kids healthy and safe." (A child in primary school, sixth grade, and in the third school, on August 3, 2017)

"Mothers' food is clean and delicious with full nutrition. My mom always cooks by her heart. My mom cooks very clean. If it was dirty, she must cook again." (A child in primary school, sixth grade, and in the second school, on August 3, 2017)

"Mother's food is a useful thing with 5 nutrient groups. The children eat and are very happy. They will not forget the taste. The family is also happy with the food that the mother made." (A child in primary school, fifth grade, and in the ninth school, on August 3, 2017)

\section{Family relationship}

Mother's cooking is a bond of attachment among mother and child and family members. Cooking is a tool for mothers to create and encourage a sense of trust, relationship and closeness to their children and family. Regardless of age, the mother's cooking is always important because the mother's food is at the heart of promoting nutrition for their children. It is considered to be the best of food that mothers gave to children and prepared for children and family members. (A child of a good mother role model sixth, on October 6, 2016).

"For some families, children told that the mother will go to the market together from 6:00 A.M. Before going, the mother asks, what would each person want to eat? She will choose to buy fresh products. The fish have to show red gills." (A child of a good mother role model first, on October 1, 2016)

"Mother's food is always delicious, not tasty at all, but we think about what the mother intends to do since choosing to buy food to cook for children. It is a family relationship. Mother cooks each breakfast, lunch, and dinner. She makes us eat from young to old. Thus, the mother's food is not a small pleasure, but it is great happiness." (A child of a good mother role model second, on October 20, 2016)

\section{Giving and sharing}

Giving and sharing were viewed as roles of mothers for maintaining and strengthening familial and social bonds through food-related activities. Some of interviewed children mentioned that the mothers' everyday cooking practices symbolize her donation of time and work to her children and family. A mother is willing to sacrifice for her children. She gets up early, waiting to cook and feed her children and could give her child a little bit more nutritious food for their growth. These experiences were declared by:

"Mother's food is the child's great happiness, hidden with love and care as well as the mother's sacrifice for children. Sometimes, even though the food is minimal, the mother agreed to sacrifice and to go hungry to make the child full. Children feel better luck than many other children who have not eaten food from his mother." (A child in primary school, sixth grade, in the fifth school, on August 3, 2017)

"Whether the mother is rich or just poor, the food that the mother makes the child eat will be full of value. Mom always gives good food to her child." (A child in primary school, fourth grade, in the seventh school, on August 3, 2017)

"Mothers' cooking is very useful. There are many menus that my mother can make delicious including clear soup, sour soup and pork bone soup. My mother cooked the best for her children. I never forgot the delicious food that my mom cooked and also the mother's generosity and sacrifice." (A child in primary school, sixth grade, in the third school, on August 3, 2017)

\section{Demonstration of love and care}

Interviewed children emphasized that mothers demonstrated their love and care for children through an act of preparing and cooking meals. Most children in this study explained that a mother never stops cooking for her children, even if the child has grown up. When her children went home late, she will wait for them to have dinner together. These descriptions identify the potential to extend love and take care for their children through the mother's cooking activity. Interviewed children also reinforced the idea that mothers' cooking, which is perceived to have been made with love, tastes more delicious, in order to show how much the mother cares.

"For mother's food, it is not only being nutritious, but it is also hidden with love and concerning for children that she gives their children. For cooking mom's food, it is not only to remove hunger. However, mom still put love attention goes down because wanting the child to be healthy." (A child in primary school, fifth grade, in the fourth school, on August 3, 2017)

"My mother's most impressive food was Tom Yum Kung or river prawn spicy soup. It is not an ordinary Tom Yom, but is also full of love and care. Mom cares for every detail of the food. No cook can compete with her. The happiness of motherhood is to cook food for children to eat. My happiness is to eat 
the food that mom made." (A child in primary school, sixth grade, in the eighth school, on August 3, 2017)

The process to produce mother's food

What are the steps? According to the perception of children of different ages and from interviews from mothers who cooks for the children, the responses showed there are various steps, as follows:

\section{Preparation process: Choose raw materials meticulously}

The participants mentioned that some mothers use ingredients from their own backyard garden for cooking. Some of them buy ingredients from the market that are carefully selected, although the price is more expensive than usual. Some of the families also raise fish in the pond, such as snakehead fish and tilapia. A 71-year-old mother said that "I have to collect fresh chili from the tree to make a delicious curry paste. Shrimp paste must be fragrant." (The mother's family: 71 years old on October 13, 2516) Every family and mother will be meticulous in preparing raw materials before cooking such as pounding coconut grater, washing vegetables, chopped mango, etc.

\section{Cooking process: Mother puts in love and transfers wisdom to children}

Transfer wisdom from mother to children in the recipe.

Participants reported that their mothers were the major source for learning basic cooking skills. While cooking, mothers keep telling their children what each step is, how to notice that the food item is cooked, and what each item should consist of. Each family has a unique recipe for cooking. Although the food is the same, the recipe is not the same. There are often delicious menus that mom makes by using steps that the mother accumulated from experience, and she keeps repeating to the children. Some mothers mentioned that teaching children to cook was like teaching life's lessons to a child. As the 71year-old mother said, "Teaching children to cook is like teaching about all of life." The mother cooked the food for her children to eat while teaching the children, until the children left the house for marriage. Some children who have separated from their families will cook for their mothers and eat together with them. (The mother's family: 71 years old on October 13, 2516)

"Sour curry must use 3 bowls of water. Mother, using this bowl, measures the water from the curry because the small children must set the fire to boil the water first. Then put the curry paste mixed with shrimp paste, then add the last fish and vegetables. (Example mother [seventh] on October 13, 2516)

"When I was a kid, I cooked omelets and fried eggs. When I was growing up, I made Sa-To fried vegetables and fried pork. To cook omelets with grandma's recipe, I made it by adding fish sauce until the color changes. It needed more water, beat eggs, and pour little oil." (Mother's child example [second] on October 10, 2517)

Some interviewed mothers said that they cook and eat together with their children because this was cultivated by their own mothers. The mother cooks food for her children to eat. It was given to the grandmother that, if raising grandchildren, she must cook for the children to eat. Thus, the lifestyle will be passed down to the grandchildren. (Example mother [tenth] on August 6, 2517)

Mother teaches nutrition principles from the food menu.

For some families whose mother has a career in public health, she will explain to the children how valuable is each ingredient that is used for cooking. For example, she explains, are there any nutrients that are beneficial to the body?

"Since I was a kid, my mom emphasized the value of nutrients. Thus, I didn't buy fried meatballs in front of the school, even though my friends bought them. My mom said that it is useless since I was young, including crunchy snacks that have never been eaten. My mom provided me to eat a lot of eggs and milk until I become addicted to that habit." (Mother's child example [first] on October 10, 2516)

\section{The process of eating together}

All participants said that in childhood after the mother had finished cooking, family members came to dine together regularly. There was a conversation during the meal. There was also storytelling for the children each day. Some parents used this mealtime to cultivate morality in their children.

Tell the story of the children encountered.

For every family whose mother cooks, children will have a meal together, especially for dinner, which occupies a lot of time. For breakfast, the mother will make simple menus such as vegetable stir-fry, 
eggs, etc, during the period that the school-aged child eats before going to school. But for the evening meal there was a long time to help prepare food, cook and sit and dine with the whole family.

The conversation at the dinner table: Each family has provided information that while eating a meal together, children often tell the stories that they encounter throughout the day. Sometimes they discuss issues with friends or hear counseling suggestions. Some issues relate to what teachers taught that day but were not understood. Sometimes there was joking with and teasing each other to know what the family members did each day. Some families say that eating together helps the food to taste better.

"Eating together at least 1 meal a day makes known what the kids have done and what the kids found; at the least we teased them. We bond with each other as they gained experience in society. I do believe that my son was bonded with our family." (Example mother [second] on October 19, 2516)

"While eating, we often tell stories about experiences that were encountered throughout the day. They consulted mother when having problems with friends, or sometimes when a teacher spoke, and they did not understand. Sometimes there are no problems, but we tell jokes after eating our fill. After eating, we have more power to do homework."

"I think the main thing is not in the side dish but eating together." "Before cooking, we come to help prepare grated coconut, pound the chili, and use the vegetable shredder. Most of the cooking is by my grandma." (Mother's child example [first] on October 10, 2516)

Eating together has become a family's rule or family tradition from generation to generation.

For some families eating together became a family rule that was passed down. Some families, for example, say that the mother is responsible for cooking meals for the family at every meal because the family members don't eat outside the house. The principle of raising children focuses on eating together at least 5 days a week. These experiences were declared in this example:

"This eating together is inherited from my father's generation. We have 10 siblings. If the children have not come together, he won't eat. However, we must wait until all eating is complete. We also teach our children to do this. Because we were together, it made me happy, sitting down, and talking about everything such as private topics and work." (Example mother [eighth] on August 10, 2517)

"Since the past, everyone in the family eats together at every meal. When the 3 children got married and left the house, they still built houses nearby, and still had time to eat together. It's a happy atmosphere and grandchildren are united." (Example mother [tenth] on July 15, 2517)

Mother cultivates morality and ethics while eating.

Families often spend the time while eating together to teach and cultivate their children as well such as to teach the children to be good and generous and to have open minds. Some families were taught not to say bad things at the dining table and to talk only about good things. These experiences were declared in this example:

"What I remember precisely is that mother taught children to be good-hearted. Before going to school, children will greet mothers by bowing. Today, those children are over 50 years old. Before going to work, they still bow to the mothers. If there is a day with a meeting far from home, and he must spend overnight, then after dinner, the child will hug his mother and say that he will go to a meeting. Mother will bless me for good luck. After returning from the meeting, I will come to embrace my mother and kiss her." (A child of a mother 91 years old)

"While eating, they were instructed not to talk about bad things." (Executive child, on October 10, 2016)

"Money cannot buy warmth. There was closeness from eating together. In the meantime, I will always tell my children that if there are any problems, tell or talk. He will tell and consult us everything. Every morning, I will prepare food for the children. If it is needed or there is an urgent travel, I will buy some food for the children. However, that's a very rare case." (Example mother [ninth] on August 3, 2517)

\section{Discussion}

The findings of this qualitative study show the complexity of meanings and dynamics around mothers and cooking. The results provided by the mothers' and children's perspectives support the previous research that shows the lack of a single definition of mothers' cooking $[17,26]$. Mothers' cooking was conceptualized depending on personal decisions. Thais perceived mothers' cooking quite differently based on whether the perspective towards mothers was as the giver or whether the children addressed the perspective of a taker. For the giver, mothers aged 31 to 80 years old identified cooking as a way to 
express mothers' love, and her role and can be defined as a 4-dimensional concept: The power of love, happiness time, self-worth and role and responsibility. For the taker, mothers' cooking is a means of receiving love and care and can be understood as a 4-dimensional concept: The best and most delicious food, family relationship, giving and sharing and demonstrate love and care.

These findings provide insights for discovering the relationship between cooking, mothers and health from multiple viewpoints. In this study, mothers intended to cook for their families. They not only conceptualize cooking as a necessary, daily routine but also as a happy task and having emotional values to practice and sustain cooking for their families. Mothers' cooking is an act of love that is passed down between mothers and families to keep them happy and healthy. The power of love reflects a common value of devoting oneself to everyday cooking activities because Thai mothers try to maintain family togetherness and the health of children as well as cultural traditions. As a result, cooking should be prioritized and integrated into one's daily routine.

Our study also shows that mothers often take pleasure in cooking and enjoy the social aspect of home food preparation for their children and families. Although prior researches have mentioned that mothers' cooking was conceptualized based on the degree of time taken or effort expended [18,27], these findings confirm that a time of enjoyment is a major component of mothers' cooking.

Mothers' cooking is also linked with a sense of purpose and self-worth whenever they prepare and cook meals. One possible explanation is that mothers engaged in a regular cooking activity that promotes feelings of confidence, community, purpose, meaning, belonging, closeness and intimacy. All of these factors for mothers have been related to improved satisfaction, reduced stress and a better overall sense of well-being.

Mothers also described cooking as a prominent role and an important part of their self-identification as a mother. This finding reflected that the spiritual importance of motherhood, the traditional significance of mothers in Thai culture, and their personal experience of being successful and responsible mothers are all intertwined in the way Thai women care for their children by daily cooking. According to the findings, mothers demonstrate that the ideology of motherhood is inextricably linked to the discourse of role and responsibility. Through their cooking practice, cooking wholesome and delicious meals helps mothers to care for their children's overall physical, emotional and social well-being. This is in line with prior research that concluded that cooking was accepted as a female task [28]. As a result, as mothers, they perform home cooking to ensure the health of their children.

On the other hand, school-age children aged 8 to 11 years old understood the meaning of "mothers' cooking" from a subjective perspective, including the cognitive and emotional values that they perceive from the multisensory, symbolic and sociocultural aspects of mothers' cooking activities. This study found that there is a strong bond between positive outcomes of home food preparation and mothers' cooking. Children not only conceptualize mothers' cooking as enhancing their own diet and health indicators but also as enhancing the family's own relationships and social connections. This is consistent with prior studies that found that home cooking was linked to the development and strengthening of family relationships and to support connections with others [31]. Additionally, sharing is a key in Thai food culture and, therefore, sharing food with family, friends and neighbors, as found in this study, is the ultimate way of showing respect. Thai women also use cooking to construct the kinship ties between givers and receivers of food and thus play an important role in describing family and social relationships.

Thai school children use the phrase "the best thing and the most delicious" to describe how food prepared by their mothers is considered to have been "made with love" and tastes better. While food prepared by mothers meets the basic needs of children, it also has a significant impact on their emotions. "The best thing and the most delicious", as found in this study, supports the view that food cooked by mothers elicits positive emotions of nostalgia, warmth and pleasure. Evidence show that good feelings have been linked to a better eating experience and the selection of healthy foods [32].

"Demonstration of love and care" could be explained within the context of Thai food culture. Mothers' cooking is more than just food. It has a lot of symbolic significance and encompasses a lot more than just nutrient intake. For Thai children, the use of mothers' cooking is a metaphor for the idea of how much love and caring mothers have for their children.

This study highlighted that mothers integrate cultural goals into their cooking by constructing a social gathering around food. Families in Thailand tend to keep together, therefore they spend a lot of time eating together as well. The process of meticulously preparing proper food items and ingredients was understood as an essential step for creating good nutritional habits. The cooking process is seen as the mothers demonstrating love and transferring their wisdom to children. The process of eating together reinforces family ties and has become a family's rule or tradition from generation to generation. 
According to previous reports, creating meals together on a regular basis helps to strengthen family bonds and communication and teaching aids for nutrition education for children $[4,33]$.

\section{Limitations}

As with any research, there is a set of limitation found in this study. First, because the informants in this study ate family meals almost every day, their mothers' cooking perceptions may differ from those of families who don't have family meals as often. Second, face-to-face interview contexts might have inclined the participants to provide socially desirable responses, particularly when mother participants were asked about their home cooking practices, which could have biased some of their answers. In an effort to reduce this possibility, the researchers used a reflective interviewing approach with adequate time for the participants to consider their responses.

\section{Conclusions}

This study discovered the meanings of mothers' cooking from the perspectives of Thais and identified the importance of both the mothers' and school-age children's perspectives. Key themes emerged regarding mothers' cooking that were related to either the perspective of mothers as the giver or to the perspective of the children as the taker. For the giver, mothers' cooking was defined in terms of the power of love, time of enjoyment, self-worth, and role and responsibility. For the taker, mothers' cooking was defined in terms of the best and most delicious food, family relationships, giving and sharing, and cooking with love. Preparing proper food items and ingredients was used as an essential step for creating good nutritional habits. Cooking activities demonstrated the mothers' love and transferred their wisdom to their children. Eating together reinforced family ties and became a family's rule or tradition from generation to generation.

\section{Acknowledgements}

The author wishes to thank the Thai Health Promotion Foundation, Thailand for their support.

\section{References}

[1] VJB Martins, TMM Toledo Florêncio, LP Grillo, M Do Carmo P Franco, PA Martins, APG Clemente, CDL Santos, MFA Vieira and AL Sawaya. Long-lasting effects of undernutrition. Int. J. Environ. Res. Publ. Health 2011; 8, 1817-46

[2] Global Health Observatory (GHO) data, Available at: https://www.who.int/gho/child-malnutrition/ en/, accessed June 2020.

[3] Food and Agriculture Organization, Available at: http://faostat3.fao.org/download/Q/QC/E, accessed May 2017.

[4] AJ Hammons and BH Fiese. Is frequency of shared family meals related to the nutritional health of children and adolescents? Pediatrics 2011; 127, e1565-e1574.

[5] JA Fulkerson, N Larson, M Horning and D Neumark-Sztainer. A review of associations between family or shared meal frequency and dietary and weight status outcomes across the lifespan. J. Nutr. Educ. Behav. 2014; 46, 2-19.

[6] JA Wolfson and SN Bleich. Is cooking at home associated with better diet quality or weight-loss intention? Publ. Health Nutr. 2015; 18, 1397-406.

[7] MS Christian, CEL Evans, N Hancock, C Nykiaer and JE Cade. Family meals can help children reach their 5 A Day: A cross-sectional survey of children's dietary intake from London primary schools. J. Epidemiol Community Health 2013; 67, 332-8.

[8] World Health Organization. Healthy nutrition: The role of woman. WHO Regional Office for Europe, Copenhagen, Denmark, 2000, p. 2-4.

[9] W Takeda, MK Melby and Y Ishikawa. Who eats with family and how often? Household members and work styles influence frequency of family meals in urban Japan. Appetite 2018; 125, 160-71.

[10] B Sen. The relationship between frequency of family dinner and adolescent problem behaviors after adjusting for other family characteristics. J. Adolesc. 2010; 33, 187-96.

[11] ME Eisenberg, D Neumark-Sztainer, JA Fulkerson and M Story. Family meals and substance use: Is there a long-term protective association? J. Adolesc. Health 2008; 43, 151-6.

[12] F Lavelle, L McGowan, M Spence, M Caraher, MM Raats, L Hollywood, D McDowell, A McCloat, E Mooney and M Dean. Barriers and facilitators to cooking from 'scratch' using basic or raw ingredients: A qualitative interview study. Appetite 2016; 107, 383-91. 
[13] S Mills, M White, W Wrieden, H Brown, M Stead and J Adams. Home food preparation practices, experiences and perceptions: A qualitative interview study with photo-elicitation. PLos One 2017; 12, $\mathrm{e} 0182842$.

[14] S Chukumnird, W Pruksasri, J Sangsawang, S Puijarone, O Rongsawat and S Pruksasri. Development of food and nutritional management model using mother's food guideline, Phawong sub-district: A participatory action research. J. Nurs. Health Care 2017; 35, 214-23.

[15] W Aekplakorn. Thai National Health Examination Survey V. Health System Research Institute, Nonthaburi, Thailand, 2016, p. 89-105.

[16] F Short. Domestic cooking skills: What are they? J. Home Econ. Inst. Aust. 2003; 10, 13-22.

[17] F Short. Kitchen secrets: The meaning of cooking in everyday life. Berg, Oxford, England, 2006, p. 27-9.

[18] M Carrigan, I Szmigin and S Leek. Managing routine food choices in UK families: The role of convenience consumption. Appetite 2006; 47, 372-83.

[19] SDH Mills, JA Wolfson, WL Wrieden, H Brown, M White and J Adams. Perceptions of 'home cooking': A qualitative analysis from the United Kingdom and United States. Nutrients 2020; 12, 198.

[20] MA Neergaard, F Olesen, RS Andersen and J Sondergaard. Qualitative description-the poor cousin of health research? BMC Med. Res. Meth. 2009; 9, 52.

[21] M Sandelowski. Whatever happened to qualitative description? Res. Nurs. Health 2000; 23, 334-40.

[22] G Guest, A Bunce and L Johnson. How many interviews are enough? An experiment with data saturation and variability. Field Meth. 2006; 18, 59-82.

[23] DF Polit and CT Beck. Nursing research: Generating and assessing evidence for nursing practice. $9^{\text {th }}$ ed. Lippincott Williams \& Wilkins, Philadelphia, United States, 2012, p. 408.

[24] JR Gray, SK Grove and S Sutherland. The practice of nursing research: Appraisal, synthesis, and generation of evidence. $8^{\text {th }}$ ed. Elsevier, Missouri, United States, 2017, p. 268.

[25] UH Graneheim and B Lundman. Qualitative content analysis in nursing research: Concepts, procedures and measures to achieve trustworthiness. Nurs. Educ. Today 2004; 24, 105-12.

[26] JA Wolfson, SN Bleich, KC Smith and S Frattaroli. What does cooking mean to you? Perceptions of cooking and factors related to cooking behavior. Appetite 2016; 97, 146-54.

[27] JC Kaufmann. The meaning of cooking. Polity Press, Cambridge, England, 2010, p.183-4.

[28] L Heslop, J Madill, L Duxbury and M Dowdles. Doing what has to be done: Strategies and orientations of married and single working mothers for food tasks. J. Consum. Behav. 2007; 6, 7593.

[29] IA Ana, D Schoolmeester, M Dekker and WMF Jongen. To cook or not to cook: A means-end study of motives for choice of meal solutions. Food Qual. Preference 2007; 18, 77-88.

[30] R Dixey. Gender perspectives on food and cooking skills. Br. Food J. 1996; 98, 35-41.

[31] D Simmons and GE Chapman. The significance of home cooking within families. Br. Food J. 2012; 114, 1184-95.

[32] C Evers, M Adriaanse, DTD de Ridder and JC de Witt Huberts. Good mood food. Positive emotion as neglected trigger for food intake. Appetite 2013; 68, 1-7.

[33] HRH Rockett. Family dinner: More than just a meal. J. Am. Diet. Assoc. 2007; 107, 1498-501. 